\title{
Privado e/ou público: querelas sobre a arte de enganar a natureza
}

\author{
Private and/or public disputes about the art \\ of fooling nature
}

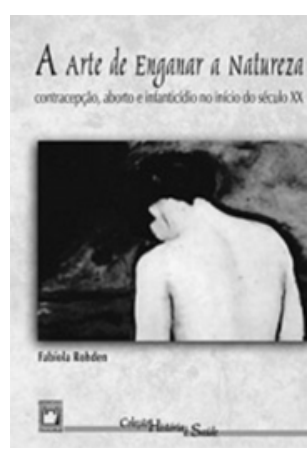

Fabíola Rohden $A$ arte de enganar a natureza: contracepção, aborto e infanticídio no início do século XX Rio de Janeiro: Ed. Fiocruz, 2003. 248 p.

\section{Jane Felipe Beltrão}

Antropóloga e historiadora, professora do Departamento de Antropologia Centro de Filosofia e Ciências Humanas da Universidade Federal do Pará Travessa Tupinambás, 1163/803 - Batista Campos 66033-815 Belém - PA - Brasil jane@ufpa.br

$\mathrm{F}$ azer Antropologia a partir de documentação histórica ou fazer História incorporando a leitura antropológica se constitui em exercício acadêmico que, ao ignorar as fronteiras disciplinares, brinda o leitor com $A$ arte de enganar a natureza, trabalho de Fabíola Rohden que usa de diferentes conhecimentos para apresentar 'contracepção', 'aborto' e 'infanticídio' como artifícios de intervenção na relação entre sexo e reprodução. Prática atribuída às mulheres que parecem 'rebelar-se' contra a missão imposta pela sociedade brasileira no início do século XX: reproduzir, dar filhos à sociedade. Mulheres que, com a 'cumplicidade' de outros atores sociais - parteiras e médicos -, rompem com a adoção de uma política mais nítida de gerenciamento da sexualidade e da reprodução, assuntos que, embora considerados como pertencentes ao mundo privado, revelam a expressão dos interesses públicos. Enganar a natureza se constituía em desafio ao domínio médico e jurídico-policial, braços fortes e zelosos da política do Estado protetor da maternidade e da infância.

A autora trabalha com fontes manuscritas - inventários das pretorias, relações de recolhimento e índices criminais - para chegar aos processos e inquéritos criminais referentes às diversas freguesias do Rio de Janeiro. Não descuidou dos periódicos - anais, boletins e revistas médicas e jurídicas -, além de tratar com igual atenção as fontes impressas: teses defendidas pelos doutores em Medicina à época. Nas fontes buscou, apesar dos muitos filtros, os depoimentos das mulheres que podem ser lidos a partir do que dizem e/ou escrevem os homens escrivãos, médicos, advogados, promotores e juízes -, para conhecer as questões relativas às restrições de filhos presentes nos debates concernentes ao assunto. Nos periódicos trabalha a repercussão dos debates sobre reprodução e controle de natalidade que se tornaram públicos, apesar de serem considerados 'idealmente' privados, delicados, reservados, dada a natureza moral do assunto. Nas teses buscou obter o pensamento oficial das elites médicas. Com o sólido lastro obtido junto às fontes, ousou articular autores, contextos de produção e demandas políticas na tentativa de urdir a trama sobre a reprodução e, mais particularmente, o controle da natalidade, indicando como assuntos de ordem privada se convertem em temas públicos em nome da relevância da população brasileira necessária ao desenvolvimento nacional com nuanças expressas de eugenia, bem ao sabor da época. 
Com a leitura dessa obra percebe-se que médicos e juristas, na medida em que querelam, mostram-se, também, interessados em definir os campos de atuação e esforçam-se em transformar a saúde da mulher num problema médico. Ao mesmo tempo o sistema jurídico-policial, acompanhando as exigências políticas, tentava punir exemplarmente os infratores. Uma contradição vem a lume com o trabalho de Rohden: a dificuldade de punir as mulheres, pois, praticar a contraconcepção, fazer aborto ou cometer infanticídio parecem contrariar a 'vocação' da natureza feminina em ser mãe. Nos documentos as mulheres aparecem freqüentemente como vítimas de espertos parteiras inescrupulosas e médicos pouco éticos -, ou seja, como seres desprovidos de vontade própria. Mas a leitura fina da autora permite ver a sabedoria e a dissimulação das protagonistas, embora fique nítido o esforço médico em discutir a loucura puerperal como surtos que acometem as gestantes, como se o estado de alteração mental fosse responsável pelo rompimento da natureza. Parecia inadmissível pensar o infanticídio, a morte violenta e ou premeditada de uma criança por ocasião do nascimento ou recém-nascido, como forma de evitar filhos.

Algumas teses defendidas pelos médicos pareceriam hoje totalmente inaceitáveis: a ignorância da gravidez ou do parto, e preocupações com a honra quando a criança era gerada fora de uma relação institucional - o casamento. Quando as mulheres incriminadas não se enquadravam nas condições que poderiam gerar desequilíbrios de ordem mental, os médicos brandiam suas armas contra as feras que de sã consciência cometiam o crime de 'enganar a natureza'.

Rohden sublinha, também, a dificuldade das investigações, pois a medicina enquanto técnica, à época, não era capaz de responder a todas as questões que o inquérito precisava esclarecer. Discutia-se muito sobre feticídio e aborto. O primeiro, enquanto ato técnico e praticado por médico, ao menos era a priori justificado. O segundo, cometido pela mãe ou por terceiros, seria necessariamente delituoso, quando não fosse espontâneo ou natural. A definição do delito parecia ser feita a partir do autor, assim sendo os médicos gozavam de maior reconhecimento e reputação. Grande parte das acusadas eram, portanto, as parteiras, bastante atuantes no período estudado, posto que nem todas as gestantes tinham acesso aos médicos. A saúde pública e o atendimento médico pelo Estado não eram generalizados, ainda estava em vigor o acionamento de socorros públicos diretamente relacionados às calamidades, especialmente epidemias.

Apesar do peso do tema, a escrita de Rohden encanta pela qualidade e delicadeza como expõe as teses dos querelantes, fazendo emergir as protagonistas das inúmeras tragédias retratadas nos inquéritos. $\mathrm{O}$ termo 'tragédia' surge aqui não no sentido de lástima e horror, mas pelo caráter dramático que envolve a intervenção dos atores, em cenário público, sobre assuntos que talvez devessem ficar na esfera priva$\mathrm{da}$, pois a 'arte de enganar a natureza' diria respeito, apenas, às mulheres. $\mathrm{O}$ discurso dos atores masculinos põe em relevo a política do Estado que torna necessária a discussão do controle de natalidade em função das estratégias políticas, trazendo à baila a valorização da vida, 
não a vida em si, mas a vida das crianças que estavam sendo geradas. A discussão sobre as formas de 'enganar a natureza' indica circulação de idéias que ultrapassam as fronteiras do Brasil e envolvem protagonistas de diferentes condições sociais, como apresenta magistralmente a autora. Esta conduz o leitor a identificar as raízes do problema e até permite pensar em sua atualidade.

Ao ler o livro, premiado como a melhor obra de Ciências Sociais lançada em 2003 pela Associação Nacional de Pesquisa e Pós-Graduação em Ciências Sociais (Anpocs), cabe ao leitor cardar os fios ideológicos nos quais vivemos emaranhados e refletir sobre possibilidades, sutilezas e delicadezas das relações de gênero, da intervenção do Estado e do drama dos protagonistas. Assim, torna-se possível concordar não com a 'arte de enganar a natureza', mas com as razões dos envolvidos nesse engano. A leitura promove uma possibilidade de compreender, em vez de julgar. Portanto, talvez sem se dar conta, Fabíola Rohden fez um libelo contra o preconceito, na medida em que realizou um trabalho antropológico de qualidade.

A leitura da obra deve começar pelo prefácio, de autoria de Marisa Corrêa, que é provocador e, ao mesmo tempo, dá indicações cirúrgicas sobre a leitura que se desdobra ao longo de seis capítulos. Nestes, discutem-se as razões políticas da reprodução na sociedade brasileira e a invasão dos espaços íntimos, que retira de mulheres e homens a decisão sobre 'procriar ou não'. Práticas relacionadas ao âmbito privado transformam-se em questões de ordem médico-jurídica que revelam as 'entranhas' do Brasil.

A autora inicia a discussão apontando como a reprodução se torna uma questão política. Em seguida, tomando as teses da Faculdade de Medicina do Rio de Janeiro, procura as definições médicas para os temas relacionados à 'arte de enganar a natureza'. Como a discussão extrapolou os muros da velha academia, Rohden folheou cuidadosamente os jornais para desembaraçar os fios das querelas presentes à época, no que constituiu o capítulo três. Insatisfeita com os resultados, nos capítulos quatro e cinco a autora busca indícios e fatos em inquéritos e processos 'motivados' por ocultação e/ou aparecimento de feto, aborto e infanticídio e, finalmente, no capítulo seis, apresenta o tom eugênico de médicos e políticos sobre as questões em foco para concluir refletindo sobre as questões que envolvem e articulam reprodução e controle de natalidade.

O tema é pesado, mas a pena de Fabíola Rohden é elegante e precisa, fazendo-nos refletir sobre a atualidade do assunto.

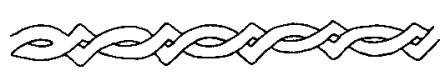




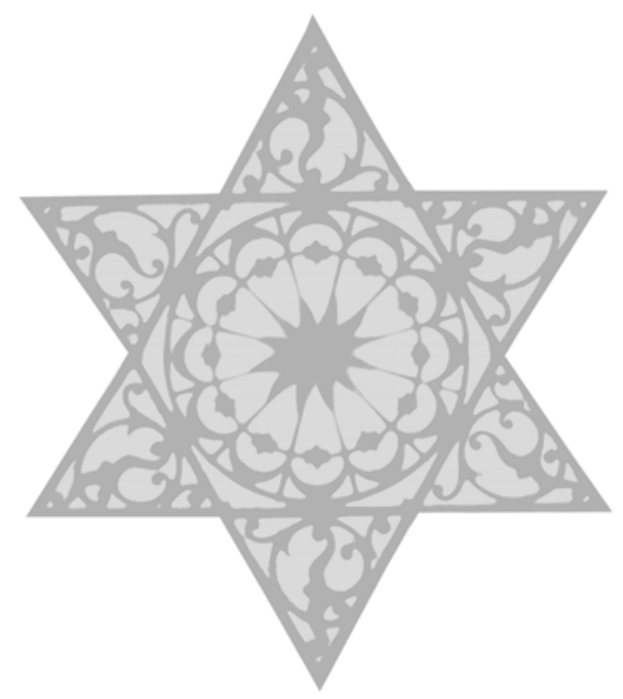

